\title{
Interactive comment on "Atmospheric
} organochlorine pesticides and polychlorinated biphenyls in urban areas of Nepal: spatial variation, sources, temporal trends and long range transport potential”' by Balram Pokhrel et al.

\section{C. Yadav}

icyadav.bhu@gmail.com

Received and published: 7 October 2017

Recent study entitled "Atmospheric organochlorine pesticides and polychlorinated biphenyls in urban areas of Nepal: spatial variation, sources, temporal trends and long-range transport potential by Pokhrel et al" is a good effort to address the issue of organic pollutants in one of the less discovered region (Nepal) located between world's two most populous countries India and China.My concerns are:

1) In my opinion, Hetauda is not an agricultural city; rather it is an industrial estate 
with a number of medium and small-scale industries particularly cement industries. on what basis author called it as agricultural cities. If you have a reference, plz cite them. 2) What recovery standard and in what amount was used in this study? 3) The climate data such as precipitation and temperature need a reference. 4) L75-76 in the supplement, is not clear as what amount of international standard was used. Also, PCB-209 may not be appropriate standard because PCBÂm209 can be detected in urban environmental samples, especially due to the emissions from pigments and dyes where it is present as a byÂmproduct (Anezaki and Nakano, Environ Sci Pollut Res (2014) 21:998Âघ1009). Hence, 13C-PCB-141 isotope labelled internal standard is most appropriate standard that compensates for errors and losses throughout the procedures 5) Why DDT is low in Hetauda despite being warmer and agricultural city? Any idea? 6) In Fig 3, How do you interpret the concentration of HCB at the industrial site (K3), why it is so high? 7) Why authors only compare and discuss their finding with past studies from India and abroad but not with the past studies of the same region. Although not many studies done in this region, but few studies are well reported (eg. Yadav et al., 2016, Guzzella et al., 2016; Guzzella et al., 2011; Gong et al., 2014, Cizmas et al., 2015 and so on) that should be consulted to discuss the finding of present data. 8) Another important concern for me is that author did monitoring of PAS for 1 year, however they compared and discussed their data with previous international studies that were based on short-term monitoring of PAS. 9) Table 1 should also include past studies of the same region to better discuss your finding.

Interactive comment on Atmos. Chem. Phys. Discuss., https://doi.org/10.5194/acp-2017-448, 2017. 